\title{
Reporting familicide-suicide in broadcast media: An Irish case study to inform better practice
}

\section{Anne O' Brien iD}

Maynooth University, Ireland

\author{
Eileen Culloty \\ Dublin City University, Ireland
}

\begin{abstract}
News media coverage plays an important role in the public recognition of intimate partner homicide (IPH) and familicide as crimes. However, studies find that news coverage typically fails to contextualise these crimes, relies on non-expert sources, and often engages in victim-blaming. Existing studies have primarily investigated print media. The lack of attention to broadcast media is significant because broadcast news attracts a larger share of public attention and it relies on distinct routines and practices that may influence coverage. To address this gap, this study presents an in-depth analysis of the broadcast news coverage surrounding a 2016 case of familicide-suicide in Ireland. Our analysis identifies patterns of decontextualisation, non-expert sourcing and perpetrator exoneration. Specifically, coverage decontextualised the crime through an emphasis on the family and the response of the community and through the privileging of (male) local sources, including male religious voices, over expert sources. Although victimblaming was not very explicit, coverage frequently exonerated the perpetrator through references to his good character. Thus, we find that broadcast news replicates the patterns of print news and that the preference for on-the ground reporting privileged sources who were proximate to the crime rather than those who could provide an expert understanding of it. These findings are discussed in terms of efforts to change media practices for more accurate representations of IPH and familicide in news media.
\end{abstract}

\section{Keywords}

Broadcasting, familicide, guidelines, intimate partner homicide

\section{Corresponding author:}

Anne O' Brien, Department of Media Studies, Maynooth University, lontas Building, Co Kildare, Ireland.

Email: Anne.obrien@mu.ie 


\section{Introduction}

Intimate partner homicide (IPH) and familicide are gendered crimes committed more frequently by men than women (Cooper and Eaves, 1996; Debowska et al., 2015). A common factor among male perpetrators of murder-suicide and familicide-suicide whereby perpetrators kill their partners or families before killing themselves - is a sense of victimisation and desire to avenge life's injustices (Harper and Voigt, 2007). Between 1996 and 2019 in Ireland, 230 women and 16 children died as a result of IPH, murdersuicide, or familicide-suicide; an average of 10 women per year (Women's Aid, 2019: 9). Of these, one in every two was killed by a current or former male, intimate partner (Women's Aid, 2019) where the intimate relationship may have been casual, hidden, dating, partnered or married (Women's Aid, 2018: 2). In almost all murder-suicide cases (21 out of 22) the killer was the woman's partner (Women's Aid, 2019: 9). Efforts to counteract IPH and familicide rely, in large part, on broadening public recognition and understanding of these crimes including awareness of the social conditions that give rise to this violence (Monckton-Smith, 2010). As academic researchers argue that news media are an important source of public mis/understanding regarding domestic abuse generally and IPH and familicide specifically, a growing number of studies explore media representations of IPH (see Richards et al., 2014). To date, studies have primarily focussed on North America, but research on Australia, Europe and Britain is growing. Importantly, the majority of these studies examine print media rather than broadcast media or social media. For example, only one study has examined social media (Twitter) representations of IPH and familicide in Ireland (Quinn et al., 2019).

The lack of attention to broadcast media specifically is a significant gap as they are a prominent source of news internationally (Newman et al., 2020) and in Ireland (Kirk et al., 2019). In Ireland, national television and especially radio are instrumental in setting the public agenda (Walsh et al., 2015) and there is a high level of trust in the public service broadcaster (Kirk et al., 2019). Consequently, it is important to understand how national broadcast media report and construct narratives about IPH and familicide. Such knowledge is a prerequisite for the development of effective media guidelines that seek to overcome problematic patterns of coverage that inhibit public understanding of and, ultimately, willingness to address violence against women as a social problem.

We may expect to find similar patterns of coverage in print and broadcast media. However, the production and presentation routines of different media influence how news is reported (Montgomery, 2007; Reich, 2016) including the use of sources and the framing of newsworthiness (Cottle, 2001). For example, the 'liveness' of broadcast media requires contributors who are willing to speak on air directly while television specifically requires compelling visual imagery through which reporters 'show rather than tell'. Any efforts to change reporting practices through media guidelines need to be attuned to the needs of a given medium (O'Brien and Culloty, 2019) but existing media guidelines are limited by their lack of attention to the concerns of broadcast news.

News reporting influences public perceptions of social reality and plays a formative role in how people understand society and social problems (Silverstone, 2007). For example, the way crime is framed by the media can influence public beliefs about crime (Cohen, 1972; Gilliam and Iyengar, 2005; Jewkes, 2015; Jewkes and Linneman, 2018). 
With regard to the murder of women, news media disproportionately report on killings involving unknown victims in public locations rather than familiar victims in domestic settings (Duwe, 2000). In this way, media coverage affects whether and how the public understands IPH as a problem and what should be done about it (Bullock, 2007: 40). By pathologising individual perpetrators or by blaming the victim, media coverage can minimise the harm caused to victims and deflect criticism from problematic social norms (Monckton-Smith, 2012: 63). As Easteal et al. note (2015: 103), 'the media frames family violence. . . using a recurrent theme of mutuality of responsibility for the violence. This contradicts the feminist understanding of these harms as gendered and reflective of male dominance, sexism and misogyny'. This needs to change in order to address violence against women.

To that end, this article seeks to: firstly, discuss the patterns of problematic media representation in newspaper representations of IPH; secondly, describe what is relevant from that research to understanding the distinct routines and practices of broadcast news production; thirdly, outline what new and unique problems arise in Irish broadcast coverage of familicide-suicide; and finally, set out the implications of these findings for better practices in broadcast journalists' coverage of IPH and familicide-suicide. The impetus for this study arose from the problematic media coverage of an Irish familicide-suicide case. In August 2016, Clodagh Hawe and her sons -Liam, Niall and Ryan - were murdered by Alan Hawe who then died by suicide. The Irish public were shocked by these events. However, the nature of mainstream news coverage drew criticism and instigated an online Twitter campaign (\#HerNameWasClodagh) that critiqued positive portrayals of the perpetrator and the erasure of the victims in coverage. This case study of broadcast news coverage seeks to identify what needs to change for a more accurate representation of IPH as a crime and social problem.

\section{Review of literature}

A compelling body of research has identified persistent problems in media coverage of IPH. Three issues have emerged as key problems: journalists often decontextualise IPH as an issue; engage in forms of victim blaming; and use limited, non-expert sources (see Sutherland et al., 2016 for an overview). Regarding the first problem, multiple studies have identified a pattern of representational practices that fail to contextualise IPH accurately: namely, a disinclination to name IPH as domestic violence and a related failure to connect IPH cases to histories of domestic violence. These patterns emerge from news producers' decisions to not use the term 'domestic violence' for IPH cases and to ignore a history of domestic violence even when the evidence is available. The causes of violent female victimisation tend to be attributed to 'individual and family pathology rather than to social structures and gendered patterns of dominance and control' (Meyers, 1994: 48). In 2000, the Rhode Island Coalition Against Domestic Violence found that less than 20\% of newspaper articles made clear reference to the type of violence involved in IPH; incidents were instead labelled as a 'family tragedy' or tragic 'love story' even when evidence of prior intimate partner violence was available. Similarly, a study of 230 newspaper articles from Washington state found that more than $75 \%$ of articles 'elaborated little' on the context of domestic violence and 'seldom labelled a killing as 
domestic violence' (Bullock and Cubert, 2002: 483, see also Richards et al., 2011). Many studies have identified the presence of an episodic frame whereby a succession of IPH cases were presented as isolated incidents rather than as a trend (Bullock, 2007; Fairburn and Dawson, 2013; Gillespie et al., 2013; Taylor, 2009; Wozniak and McCloskey, 2010). The consequences of this omission are that mainstream newspaper coverage ignores the gendered nature of the violence. Not using the term domestic violence or intimate partner homicide 'sidesteps the issues of male control, manipulation and abuse of women' (Bullock and Cubert, 2002: 483).

The second key problem with media reporting of IPH is the allocation of blame (Sutherland et al., 2016). Reporting sometimes frames the parties involved as 'different' from ordinary people, directly or indirectly blames the victim, or exonerates or excuses the perpetrator. By stereotyping the victim and excusing the perpetrator as ill, mad or provoked, news producers fail to show their audiences that intimate partner homicides occur after a pattern of escalating abuse and previous threats (Johnson and Dawson, 2011; Monckton-Smith et al., 2017). By excusing and exonerating perpetrators or by portraying their actions in a neutral fashion, news stories can lead the public to believe that the female victim is the one in control of (or to blame for) the situation (Jewkes, 2011). Meyers (1994) was the first to note that the allocation of blame came from journalists' attempts to explain why domestic violence occurs and that an underlying patriarchal ideology shaped who was blamed in news coverage. Bullock and Cubert (2002) subsequently found, in their Washington State sample of 230 newspapers, that $48 \%$ of articles suggested at least one motivation or excuse for the perpetrator. Evans (2001: 150) observes in her case study of homicide reporting that women were 'shot, killed, cried for, apologised to, but not according to headlines actually murdered'. Bullock (2007) identified additional ways in which the perpetrator was set apart. For example, by referencing place of origin whereby perpetrators were commonly framed as outsiders to the location in which the murder occurred. Taylor's (2009) study identified direct approaches to victim blaming including using negative language to blame the victim's 'inadequate' response to her situation; blaming her for not pursuing a prosecution; and describing her interactions with other men as a contributory factor in her murder. Indirect approaches to blame included 'using sympathetic language to describe the perpetrator' (Taylor, 2009: 21). This involved describing the killer's stress, hardships, ailments, family background, mental health issues and financial problems as mitigating factors or describing the murder in terms of the perpetrator 'snapping' (Taylor, 2009). Similar findings were offered by Richards et al.'s (2011) analysis of femicide-suicides, coverage used blame mechanisms by 'explaining' perpetrator actions through loss of control (14\%), perpetrator jealousy (3\%) and 'mercy' killings (4\%) (2014: 37). Niblock (2018) similarly notes that murder-suicide reports often blame women for "leading a loving father to "snap"'. Cavaglion (2009: 131) examined filicide by fathers in Israel and noted that the press 'makes the story easy, clear, readable, understandable but also stereotyped'. Jewkes (2011: 147) and Little (2018) notes that sympathy is often shown towards men who kill their intimate partners in media reports that construe such events as a 'tragic' cases of decent husbands or doting dads gone wrong. While Fairburn and Dawson (2013) identified a reduction in the blame frame over time, from $29 \%$ in the 1970 s to $14 \%$ in the late 1990 s, they nonetheless found that coverage continues to employ victim-blaming news frames. 
The third major problem with the framing of IPH and familicide stories is the selection and use of sources to comment on events. Research shows that the police tend to be the most used source. Neighbours and bystanders are also regularly engaged for comment while domestic violence advocates or victims are rarely approached. Bullock (2007) notes that sources are most likely to be police or court contributors. Some $57 \%$ of the articles reviewed by Richards et al. (2011) used the criminal justice system as sources and noted that police officers tend to offer 'overly simplistic descriptions' as to why the murder occurred, such as single specific reasons like an 'argument over cigarettes'. Bullock and Cubert (2002: 493) similarly note that the use of police as sources is problematic because they tend to emphasise the 'what, where, when and how of the crime' rather than it's link to an overarching pattern of similar crimes. Taylor's (2009: 37) analysis identified a link between the use of police and defence attorney sources and a tendency to blame the victim. Apart from the police and judiciary, journalists 'routinely look to the neighbours of a couple or other members of the community for information about a couple in femicide coverage [which] serves to perpetuate harmful myths about domestic violence' (Taylor, 2009: 27). Richards et al. (2011: 191) found that 37\% of the articles they reviewed used 'private' sources such as friends or family while only $6 \%$ used domestic violence experts. Carlyle et al. (2008) further observed that only 5\% of articles provided any information regarding domestic violence experts or resources such as shelters, websites or support-lines.

The cumulative effect of this pattern of sourcing means that a story will not be framed as domestic violence unless the police state that there was a previous record of reported incidents or of coercive control. 'Relying solely on police for this information leads to false portrayals of the context of femicide' (Taylor, 2009: 27). In other words, just because police have no records does not mean that there was no history of domestic violence or coercive control, use of criminologists as additional expert sources on the nature of familicide-suicide could, for instance, offer journalists alternative contexts through which to report the crime. Secondly, relying on police sources also tends to portray solutions to gender violence as resting with male-dominated institutions and does not challenge the overarching context of patriarchal systems within which violence against women occurs. As Richards et al. (2014) note, the absence of domestic violence experts means that coverage fails to explain the difficulty of severing an abusive relationship; fails to identify any links between an individual murder and the extent of domestic violence patterns locally or nationally; and fails to document the impact of femicide on the family, community and society.

As noted, studies of IPH coverage - and by extension media guidelines for reporters have neglected broadcast media. The lack of attention to broadcast media is significant because, in contrast to print, broadcast news attracts a larger share of public attention and it relies on distinct production routines and practices that influence how news is reported (Montgomery, 2007; Reich, 2016) and generate time and organisational pressures on journalists (Reich, 2016).

Of particular interest to this study are news and current affairs programmes. In contrast to short news bulletins, news and current affairs programmes go beyond reporting the facts to provide additional comment by journalists, politicians, experts and other figures (Chignell, 2013). The genre and the demands of broadcasting shape choices about who 
and what to include. Typically, news and current affairs programmes prioritise dialogue that is personal or emotionally engaging (Thornborrow and Montgomery, 2010). This creates a preference for sources that are available for live transmission and likely to provide engaging dialogue. Although news and current affairs programmes are broadcast live, it is not uncommon to include short features that have been pre-recorded by journalists. Arguably, these features afford reporters time to think about how a story is framed, to review the language and to seek out relevant sources. Finally, broadcasting is more tightly regulated than print media and there are regulatory and cultural differences between broadcasters. For example, public service broadcasters are expected to comply with editorial codes of practice and are generally found to be less sensational than their commercial counterparts (Vettehen et al., 2012). As these factors potentially influence broadcast coverage of IPH, this study investigates the broadcast coverage of an Irish familicide-suicide case to understand whether and how problematic patterns of coverage are manifest and to assess the implications for developing effective media guidelines.

\section{Methodology}

This study is based on a qualitative content analysis of national broadcast coverage in the week following the Hawe familicide-suicide. The selection of programmes for analysis reflects the scope of news and current affairs programming in Ireland. In addition to news bulletins, we are specifically interested in news and current affairs programmes that go beyond reporting the facts to provide comment and analysis (Chignell, 2013). In Ireland's small market, only two national television stations and three national radio stations provide in-depth, news and current affairs programming. Among these, the radio and television services provided by the public sector broadcaster are by far the most widely used and trusted news sources (O’Brien and Culloty, 2019). Radio is notably prominent in Ireland with many hours of current affairs programming and high listenership levels (Walsh et al., 2015). To reflect the radio market, we selected the drivetime programmes from the public sector broadcaster (RTÉ) and the two commercial news broadcasters (Newstalk and Today FM). Given the prominence of the public sector broadcaster, its flagship morning programme was also included. On television, the main evening news programmes by the public sector broadcaster and the commercial broadcaster (TV3) were included.

The time-period for analysis encompasses a 6-day period from Monday August 29th 2016 when news of the crime was first reported to Saturday September 3rd 2016 when the funerals took place. To understand the trajectory of coverage, any item about the case across each date was recorded (see Table 1). The relevant broadcasts were saved and the items were transcribed for coding and analysis.

The study follows Peelo and Soothill's (2012) 'social questioning' approach to identify the rhetorical and linguistic practices through which a public narrative of crime is constructed by the media. The coding frame assessed each item using a set of criteria reflecting the issues identified in the IPH literature. Of particular interest are the rhetorical practices through which news media construct crime by picking out certain details as exceptional or newsworthy (Peelo et al., 2004) and by excluding certain details that may 
Table I. Broadcast news programmes that covered the Hawe familicide.

Monday Tuesday Wednesday Thursday Friday Saturday

29/08/16 30/08/16 31/08/16 01/09/16 02/09/16 03/09/16

Radio: drivetime news programmes

RTÉ 'Morning Ireland'

RTÉ 'Drivetime'

Newstalk 'The Right Hook'

Today FM 'The Last Word'

Television: evening news programmes

TV3 'The 5:30'

RTÉ 'Six One'

contextualise a deeper understanding of the crime. Each item was reviewed multiple times and coded to identify the presence or absence of information in the following categories:

\section{Use of sources}

Police sources and local sources such as neighbours and bystanders contributes to the decontextualisation of IPH. The sources used in each item were recorded along with the given description of the source, the accompanying claims or quotes and whether the source was quoted directly or indirectly.

\section{References to the perpetrator}

Any reference to perpetrator's motivation was recorded for each item, including the source of the claim, and, as relevant, any accompanying imagery.

\section{References to victims}

Each item was coded for the inclusion of any references of the victims, the nature of the reference (e.g. demographic details), the source of the claim and, as relevant, any accompanying imagery. Indeed, news media coverage of the Hawe case received considerable criticism for failing to name the woman victim. To address this, the study quantitatively coded any named or unnamed (e.g. a man) references to the perpetrator and victims.

\section{References to domestic violence}

Each item was coded for the inclusion of any references to domestic violence, IPH, familicide or coercive control as a potential context for the crime, the context of the reference and the source of the reference. 
In addition, the specific topic (e.g. inquest, funerals), the use of imagery in television broadcasts (e.g. photographs, footage from the location) and comments about specific issues such as the use of sensational language or imagery were also recorded.

\section{Findings}

The key finding is that the problematic patterns of international print coverage of IPH are replicated in broadcast news reporting. Inappropriate sourcing, decontextualisation and exoneration of the perpetrator were in evidence across radio and television coverage. Regarding the broadcast news genre, we find that broadcast journalists privilege proximity to the crime over expertise in criminology. In the Irish context, this meant that religious community leaders were used as key commentators rather than experts in gender violence or crime. In the trajectory of coverage, we find a significant time delay before journalists look to domestic violence experts as sources. Throughout coverage, male voices were privileged over female voices despite the fact that women suffer disproportionately as victims of IPH and familicide. The use of inappropriate sources contributed to the decontextualisation of the crime: religious commentators spoke of mystery, faith and prayer - themes not normally included in hard news programming and journalists' questioning of sources emphasised emotional frames about the 'ordinary' family, as if some obvious characteristic should have designated them likely to die in a familicide-suicide. The construction of these themes is discussed in detail in what follows.

\section{Decontextualisation and 'family'}

The case reflects the international research which finds that coverage of IPH is often decontextualised. Across all coverage, no broadcaster interviewed a criminologist with expertise in familicide or murder-suicide and no national politician was questioned about resources for tackling coercive control. The exclusion of these sources suppressed the relevant context. Another subtle mechanism through which journalists suppressed the contextual connection between the case and domestic violence or coercive control was the emphasis on family. Subtle references to 'family' repeated implied that, despite all appearances, the Hawes were not a 'normal' family and by extension that domestic violence or coercive control is not a feature of 'ordinary' families, but something that occurs only to 'othered' families.

On August 29th, the day of the murders, reporters drew heavily on coded language that drew a distinction between a 'normal' family and a family in a domestic violence or coercive control situation. A local journalist appeared on RTÉ 'Drivetime' and stated four times that the family were 'well known in the community'. This mantra was repeated by a local politician, who described the family as 'well known' three times. Similarly, Newstalk radio mentioned the family as 'prominent members of the community' while TV3 television news asked if they were 'a very popular and well-liked family'. Emphasising the characteristic of being 'known' and active in the community conveyed the idea that domestic violence or coercive control is atypical for an apparently normal family, it is something that could only happen to 'other' types of family. 
Throughout the week, references to the 'family' unit were notably prominent, despite the fact that four members of the family had been murdered. On television, RTÉ referred to the 'family' six times in a short report on August 30th and while TV3 referred to the 'family' eight times in a report on funeral arrangements that lasted 1 minute and $23 \mathrm{sec}$ onds. In the funeral coverage at the end of the week, the family were still referred to as a unit: 'friends and neighbours attending prayers in memory of the whole family' (RTÉ Six One 03/09/16). Both broadcasters consistently referred to the bodies in an order leading with: 'Alan Hawe, his wife Clodagh and their three young sons'. Even before the victims were named, the deaths were listed beginning with Alan Hawe and his victims were defined in terms of their relationship to him. For instance, the 'deaths of a man, his wife and their three sons' (RTÉ Six One 29/08/16) and 'the bodies of a man in his 40s, his wife aged in her 30s and their three sons. .' (TV3 News at 5:30 29/08/16). This framing reinforced the traditional patriarchal family structure with every member defined in relation to the head of the household, despite the fact that he was their murderer. Coverage consistently failed to make a distinction between the murderer and the murdered and the 'tributes' during the funeral are described as applying equally to all. In the context of family, journalists appeared to overlook the four murders and to abandon the hard news conventions of reporting murder. Journalists failed to make a distinction between murder and suicide as causes of death and declined to make any reference to the pre-meditated murderous betrayal that occurred within that 'family'.

The morning after the familicide-suicide, RTÉ's 'Morning Ireland' (30/08/16) aired extensive commentary from Bishop Leo O' Reilly who emphasised traditional ideas of family and offered religious faith and mystery as a context for understanding the crimes. This framing precluded any criminological understanding by presenting the murders as a test of Catholic faith: 'I think hope is very important in this situation and our faith that death is not the end and even the greatest tragedy that God can use this in some way that we don't understand at all and bring some good out of it'. In terms of directing a public and political response to such crimes, this framing invited only prayers: 'I think we just have to think of them and those affected by it and keep them in our thoughts and prayers at this very difficult time'. Bishop O' Reilly's religious framing was also featured on commercial television (TV3 News at 5.30 30/08/2016) and radio (Today FM The Last Word 30/08/2016); the latter included a clip of him saying 'death is not the end'. That strain of religious stoicism and fatalism is highly questionable as a dimension of what was supposed to be news coverage of multiple-murders. The bishop's comment that 'unfortunately there are no answers and we simply don't understand' (RTÉ Drivetime 30/08/16) belies the extensive criminological research and expertise on murder-suicides that could have offered a more thorough and evidence-based assessment of the Hawe case than the religious context offered.

Ultimately, revealing more of the typical factual context of IPH and familicide-suicide might better serve to educate the public on the dangers of coercive control and domestic violence. This failure to correctly frame the story misses the opportunity for a meaningful call to action for the state to address this problem with appropriate resources for education and prevention. In a similar way, outlined below, placing responsibility with perpetrators rather than exonerating them of blame might also serve to make the public aware of the gendered and controlling dynamics that underpin domestic violence. 


\section{Sources}

In their choice of sources to comment on the Hawe case, broadcast journalists across all output tended to reflect the same problematic practices outlined in the literature on print journalism. They privileged images and voices of the police, neighbours and bystanders while domestic violence advocates were rarely used as sources. Broadcasters also incorporated an additional, perhaps particularly Irish, practice of including church leaders as commentators.

On August 29th, the day of the murders, the main source of information on RTÉ radio and television was the station's crime correspondent. This clearly framed the story as crime, but also placed emphasis on the police as the main sources of information and actors within the narrative. Using the familiar language of crime reports, the correspondent noted the police were 'not looking for anyone else at present', but did not name the deaths as IPH or familicide-suicide. The two commercial radio stations did name the crime as a murder-suicide, but the description was passive and offered no clarity as to who had murdered whom. At this juncture, journalists appear to have been unaware that the perpetrator had left a note, which indicated a pre-meditated approach to the murders. The failure of the police to disclose this information to journalists inhibits accurate reporting and sets up public narratives that misunderstand the crime as inexplicable and therefore as an unpreventable 'tragedy'. In the context of crime reporting, journalists generally feel that they simply 'cannot go there' to make a connection to domestic violence without a police source to corroborate that angle (Cullen et al., 2019).

A new feature of sourcing patterns found in this Irish case was that broadcasters prioritised contributors with a geographical proximity to the crime rather than relevant experts. In early coverage, RTÉ interviewed a politician, a councillor for the local area (RTÉ Drivetime 30/08/16). He indirectly identified the as yet unnamed family by revealing that the father was Vice Principal of the local school and the treasurer of a local sports club. This mistake speaks to the problem of privileging local voices over expertise. It also established a pattern whereby generally male sources offered local knowledge and their familiarity with the perpetrator placed emphasis on him and erased the victims from coverage of their own deaths. On the second day of coverage, RTÉ's 'Morning Ireland' opened with a vox-pop of responses from bystanders, none of whom added the kind of information or expertise normally privileged in the news genre. For example, one neighbour featured here also appeared on both television stations $(30 / 08 / 16)$. He described the incident as a 'bolt from the blue', spoke mainly of his impressions of the perpetrator, and failed to mention the four victims. This continued the shift in attention from victims to perpetrators that increased the erasure of Clodagh, Liam, Niall and Ryan, which had begun the previous day. In a bizarre and unprofessional exchange, RTÉ's crime correspondent positively framed the perpetrator by quoting an unnamed bystander who had said he 'looked up to' the perpetrator (RTÉ Six One 30/08/16). As noted, the Catholic bishop, Leo O' Reilly, was a key source for commentary across radio and television coverage on August $30^{\text {th }}$. He framed the story in heavily religious terms as a 'tragedy' and a 'most difficult cross' and spoke of keeping the community in 'prayers'.

Three days passed before any reporter explicitly named Alan Hawe as the murderer and explicitly connected the murders to domestic violence. As part of its hourly news 
Table 2. Mentions of victims/perpetrator by programme.

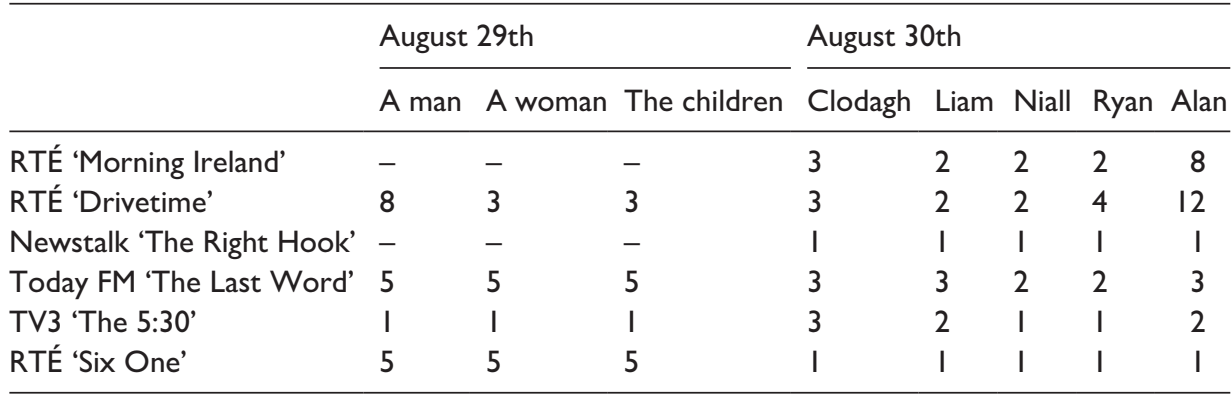

bulletin, Today FM reported that the domestic violence helpline run by Women's Aid had seen an increase in callers following the familicide-suicide (Today FM 31/08/16). The report included a brief clip from the Director of Women's Aid who commented that the deaths had 'caused a high level of distress, fear and anxiety for women. . . with concerns for themselves and the safety of their children'. The news bulletin did not go beyond that observation to access Women's Aid's expertise on the patterns and characteristics that underpin IPH and to connect that understanding to the specifics of the Hawe case. Across coverage, this short news bulletin was the only instance in which a domestic violence expert was included. In other coverage, the only helpline that was referenced live on air was The Samaritans, a suicide helpline.

In sum, sources were as problematic in Irish broadcasting as they have been revealed to be in print. In the Irish case, the police failed to name the crime, its perpetrator and the planned nature of the murders. In addition, bystanders, mostly male commentators, spoke mainly about the male perpetrator while male religious leaders reframed the murders as 'tragic', mysterious, requiring prayer. Additionally, there was a systematic failure to use domestic violence experts or advocates. Those patterns were equally problematic when it came to setting stories of IPH in their correct context of coercive control and domestic violence.

\section{Blame or exoneration}

We find that coverage frequently exonerated the perpetrator of blame in many ways: he was not named as the perpetrator, the premeditated nature of his crimes was consistently underplayed, and he was presented in a neutral or even a favourable light. Coverage placed emphasis on the perpetrator as evidenced by the imbalance in the number of mentions each person received. The children Ryan and Niall were each mentioned 25 times, Liam was mentioned 26 times, Clodagh was mentioned 30 times and Alan Hawe was mentioned 54 times (see Table 2).

On the first day of coverage the references to various members of the family were fairly balanced - the exception is the public sector broadcaster- and nobody was individually named at that juncture. At this point, no names are mentioned but 'the children' were referred to on three occasions, the 'oldest child' twice, the 'mother' three times but the 'man in his forties' had eight statements made about him. On the second day of radio 
coverage the family were named publicly. On RTÉ 'Morning Ireland', the main presenter described a photo of Alan Hawe with Liam, Niall and Ryan, which had appeared in national newspapers. Thus, the tendency to foreground Alan Hawe rather than Clodagh begun in print coverage (Quinn et al., 2019) was carried over into broadcast coverage. Only one outlet, TV3, afforded more mentions to Clodagh. This appears to be because the journalist interviewed a female bystander who recalled seeing Clodagh the previous weekend. This again underscores the randomness of relying on bystanders as sources of information. On Newstalk (30/08/16) each family member was mentioned once but Alan Hawe was described in more detail as 'the man in his 40 s, who was Deputy Principal in Castlereagh National School, he killed his wife and his three young lads by stabbing them to death before taking his own life'. The attention given to Alan Hawe was at least concerned with naming his crime clearly, a distinction that many other reports failed to make.

Coverage by the public broadcaster is notable for focusing on the perpetrator (see Table 2). On RTÉ's 'Six One' news (30/08/16), Alan Hawe was mentioned in six different ways: as the Deputy Principal who killed his wife and children; as the man in a photo attending a basketball event; as the treasurer of a local sports club; as a man that a neighbour said he would go to for help; as someone who was always reliable and positive and, bizarrely, as someone a bystander would 'look up to' if any other family had been murdered. The only mention of Clodagh Hawe during that entire main evening news broadcast was in relation to the actions of Alan having 'killed his wife Clodagh and their three young children' (RTÉ 30/08/16). The boys were named once, their ages were listed, and their participation in sports and music were mentioned. They got two sentences in a broadcast that featured a crime correspondent, a neighbour, and hearsay from a bystander including neutral and positive statements about the murderer. Clodagh, Liam, Niall and Ryan as the victims, and as people who merit tributes, comment and description, were underrepresented, most notably on the public service station, while disproportionate attention went to their murderer.

While Alan Hawe was mentioned more than anyone, the coverage was not concerned with his role as the perpetrator of murder. Instead, it focussed on very sanguine descriptions provided by his neighbour in particular. On Drivetime's second day of coverage Larry McGinn claimed Alan Hawe was someone he knew 'very, very well' as 'easy-going and ready to help out'. He mentioned Clodagh and the children only as people he 'knew well' but sadly he failed to describe them at all. When asked if there was any 'indication that there was anything wrong in the home' the neighbour authoritatively stated 'No absolutely not. Definitely. I was a very near neighbour and met them quite often. No absolutely not. . .' but McGinn did not say that he ever spent any time inside the home nor that he had any relationship with Clodagh or the children. Later Clodagh's family would clarify the control that was exerted within that home by Alan Hawe (RTÉ Claire Byrne Show, 2019). Asking neighbours questions that they had no expertise to answer did not add to the public understanding of a specific news story nor to coercive control, domestic violence or murder-suicide more generally. The ways in which Alan Hawe was represented did not serve to lay blame, responsibility or sanction where they belonged, with him.

In short, a consistent and very obvious pattern emerges in the first 2 days of coverage whereby Alan Hawe was given more attention on the public service broadcaster than the people he murdered. Unsurprisingly, the nature of this broadcast coverage, which was 
mirrored in print coverage, provoked anger and instigated an online campaign \# HerNameIsClodagh (Quinn et al., 2019).

\section{Discussion: Generating change}

In general, guidelines for reporting on domestic violence recommend that journalists contextualise it as a social, not individual, problem; present relevant local statistics about the extent of the problem; avoid promulgating myths; focus on warning signs and obstacles for women seeking to leave abusive partners; use accurate, non-judgemental language; and avoid blaming women for violence perpetrated against them (Sutherland et al., 2016). In addition, most guidelines recommend that journalists consider how sources can shape the public's understanding of domestic violence. For example, they suggest that reporters: avoid using distant acquaintances who know little about the incident; do not rely exclusively on police as sources; and seek expert voices such as survivors and advocates (Sutherland et al., 2016). However, existing guidelines were largely developed in consideration of print media and afford only limited attention to broadcast media.

Nevertheless, our study finds evidence that broadcast news is subject to the same problematic coverage patterns as print. There was a complete failure to use criminologists or domestic violence advocates as sources who could more expertly contextualise the story for the public. The perpetrator was exonerated of blame by not being presented as the perpetrator of the murders but instead being presented in a neutral or even a favourable light, with the premeditated nature of his crimes consistently underplayed. Throughout the coverage voices of male sources were privileged and women's contributions were minimal. Some aspects of the coverage speak to normative ideas about Irish culture: coverage placed heavy emphasis on the normativity of the family unit and this was reinforced by the use of religious leaders as sources. Moreover, these religious frames displaced narratives of crime and social problems with narratives of stoicism, mystery and faith. This would suggests that any guidelines need to also attend to the cultural context in which broadcasters operate.

Regarding the needs of broadcast media specifically, we find that sourcing relied heavily on local sources willing to speak live on air from the location of the crime. Bystanders were used to offer local detail and spoke only to their limited knowledge of the family, which was generally of the perpetrator. In addition, religious leaders with no expertise on the subject were called to represent the community and to speak to the family's role in it. While such sources may reflect broadcast media's preference for emotionally engaging dialogue (Thornborrow and Montgomery, 2010), they also serve to decontextualised the crime as a mystery beyond comprehension. Aside from emotional engagement, it appears that initial broadcast coverage aimed to report live from the scene. This too privileged local sources over and above experts who might contextualise the crime as a social problem. For example, relying on bystanders and community figures as a source of insight into domestic affairs is a dubious practice. Yet, journalists questioned neighbours and bystanders as to whether they could have anticipated the crime. Moreover, we find that the selection of bystanders for comment impacts on whether the coverage affords attention to the victim. In the case discussed here, the use 
of male bystanders and local figures privileged those with a connection to the perpetrator. Thus coverage offered a fuller picture of his life and, at times, a positive picture of his character.

Thus, it appears that a challenge for broadcast reporting of IHP is finding ways to redirect the assumed need for insider perspectives towards more balanced or serious coverage of crime rather than community tragedy. Tellingly, we find only one instance in which a domestic violence expert was included and that short news bulletin afforded little space to explore that expert context. Perhaps surprisingly, we find that the public sector broadcaster tended to place more emphasis on the perpetrator than commercial broadcasters. This is surprising because public sector broadcasters are thought to engage in less sensational coverage than their commercial counterparts. Moreover, they are expected to follow stricter editorial guidelines for news coverage. Further research is needed to understand why this is the case.

Although there has been some international success in developing reporting guidelines, little is known about the effectiveness of their implementation. Implementing change in the culture of media reporting may require going beyond the provision of guidelines to also fostering ongoing engagement with journalists and providing guidance to news media institutions. As Sutherland et al. note (2016: 11), 'while most guidelines describe the process by which the recommendations were developed, albeit briefly, few note implementation or dissemination strategies'. This is a significant gap in knowledge as it impedes our understanding of the circumstances that may stimulate a change in reporting practices. Potential reforms include: changes in news practice, changes in the training of journalists and the development of institutional guidelines for the coverage of domestic violence murders (Ryan et al., 2006: 213). Changes within police attitudes and practices of information sharing can be even more central to changing the culture of reporting on domestic violence than internal media changes (Simons and Morgan, 2018). This in turn points to the broader need for close engagement between journalists, police and domestic violence advocates so that all parties can share concerns about how to report IPH and familicide-suicide so that society can better understand the causes and consequences of crimes like the murders of Clodagh, Liam, Niall and Ryan Hawe.

\section{Conclusion}

In some respects, the Hawe case exemplifies what Soothill et al. (2002) describe as 'mega cases' of homicide. Mega cases are those that particularly offend society and become a reference point for understanding subsequent homicides. Notably, the outrage surrounding the Hawe case was driven in part by an objection to the media coverage (Quinn et al., 2019). Ultimately, we argue that existing media guidelines for coverage of domestic violence and IPH are limited by their lack of attention to the concerns of broadcast news and suggest that guidelines need to address the practical needs of journalists and the public need for accurate coverage. Although we found evidence that broadcast coverage replicates patterns of print coverage, we also find that the production and presentation routines privileged inappropriate sources; sources that were valued for the geographic proximity to the crime rather than any informational value. In addition, and somewhat surprisingly, we found that the public sector broadcaster's 
coverage was, in many respects, more problematic than that of the commercial broadcasters. Understanding the reasons for this - that is, the influence of different broadcasting cultures and environments - is thus an important avenue for future research.

\section{Funding}

The authors disclosed receipt of the following financial support for the research, authorship, and/ or publication of this article: Community Foundation for Ireland.

\section{ORCID iD}

Anne O’ Brien (iD https://orcid.org/0000-0003-2306-1415

\section{References}

Bullock CF (2007) Framing domestic violence fatalities: Coverage by Utah newspapers. Women's Studies in Communication 30(1): 34-63.

Bullock CF and Cubert J (2002) Coverage of domestic violence fatalities by newspapers in Washington state. Journal of Interpersonal Violence 17: 475-499.

Carlyle KE, Slater MD and Chakroff JL (2008) Newspaper coverage of intimate partner violence: Skewing representations of risk. Journal of Communication 58(1): 168-186.

Cavaglion G (2009) Fathers who kill and press coverage in Israel. Child Abuse Review 18: 127-143. Chignell H (2013) Current affairs radio. In: Allan S and Fowler-Watt K (eds) Journalism: New Challenges. London: Taylor \& Francis Ltd, pp.79-97.

Cohen S (1972) Folk Devils and Moral Panics: The Creation of the Mods and Rockers. London \& New York: Routledge.

Cooper M and Eaves D (1996) Suicide following homicide in the family. Violence and Victims 11: $99-112$.

Cottle S (2001) Television news and citizenship: Packaging the public sphere. In: Bromley M (ed.) No News Is Bad News: Radio Television and the Public. London: Longman, pp.61-79.

Cullen P, O'Brien A and Corcoran M (2019) Reporting on domestic violence in the Irish media: An exploratory study of journalists' perceptions and practices. Media Culture and Society 41(6): 774-790.

Debowska A, Boduszek D, Dhingra K, et al. (2015) The role of psychopathy and exposure to violence in rape myth acceptance. Journal of Interpersonal Violence 30(15): 2751-2770.

Duwe G (2000) Body-count journalism: The presentation of mass murder in the news media. Homicide Studies 4: 364-399.

Easteal P, Holland K and Judd K (2015) Enduring themes and silences in media portrayals of violence against women. Women's Studies International Forum 48: 103-113.

Evans L (2001) Desparate lovers and wanton women: Press representations of domestic violence. Hecate 27(2): 147-174.

Fairburn J and Dawson M (2013) Canadian news coverage of intimate partner homicide: Analysing changes over time. Feminist Criminology 8(3): 147-176.

Gillespie LK, Richards TN, Givens EM, et al. (2013) Framing deadly domestic violence: Why the media's spin matters in newspaper coverage of femicide. Violence Against Women 19(2): $222-245$.

Gilliam FD and Iyengar S (2005) Super-predators or victims of societal neglect? In: Callaghan KJ and Schnell F (eds) Framing American Politics. Pittsburg: University of Pittsburg Press, pp.148-166.

Harper DW and Voigt L (2007) Homicide followed by suicide an integrated theoretical perspective. Homicide Studies 11: 295-318. 
Jewkes Y (2011) Media and Crime, 2nd edn. Thousand Oaks: SAGE.

Jewkes Y (2015) Media and Crime, 3rd edn. Thousand Oaks: SAGE.

Jewkes Y and Linnemann T (2018) Media and Crime in the US. Thousand Oaks: SAGE.

Johnson H and Dawson M (2011) Violence Against Women in Canada: Research and Policy Perspectives. Ontario: Oxford University Press Canada.

Kirk N, Culloty E, Kearns C, et al. (2019) Reuters Digital News Report: Ireland. Dublin: Broadcasting Authority of Ireland.

Little J (2018) Filicide, journalism and the 'disempowered man' in three Australian cases 2010 2016. Journalism. Epub ahead of print 4 November 2018. DOI: 10.1177/14648849188009739.

Meyers M (1994) News of battering. Journal of Communication 44: 47-63.

Monckton-Smith J (2010) Relating Rape and Murder: Narratives of Sex Death and Gender. Basingstoke: Palgrave Macmillan.

Monckton-Smith J (2012) Murder, Gender and the Media. Basingstoke: Palgrave Macmillan.

Monckton-Smith J, Szymanska K and Haile S (2017) Exploring the Relationship Between Stalking and Homicide. Cheltenham: University of Gloucestershire, in association with Suzy Lamplugh Trust.

Montgomery M (2007) The Discourse of Broadcast News: A Linguistic Approach. London \& New York: Routledge.

Newman N, Fletcher R, Schulz A, et al. (2020) Reuters Institute Digital News Report 2020. Oxford: Reuters Institute for the Study of Journalism.

Niblock S (2018) He just snapped. Journalism Studies 19(16): 2451-2469.

O'Brien A and Culloty E (2019) Guidelines or Guidance? Changing Media Reporting of Domestic Violence Homicides in Ireland. Dublin: The Community Foundation for Ireland.

Peelo M, Francis B, Soothill K, et al. (2004) Newspaper reporting and the public construction of homicide. British Journal of Criminology 44(2): 256-275.

Peelo M and Soothill K (2012) Questioning homicide and the media: Analysis of content or content analysis? In: Gadd D, Karstedt S and Messner SF (eds) The Sage Handbook of Criminological Research Methods. Los Angeles: Sage Publications, pp.244-252.

Quinn F, Prendergast M and Galvin A (2019) Her name was Clodagh: Twitter and the news discourse of murder suicide. Critical Discourse Studies 16(3): 312-329.

Reich Z (2016) Comparing news reporting across print, radio, television and online: Still distinct manufacturing houses. Journalism Studies 17(5): 552-572.

Richards TN, Kirkland Gillespie L and Smith MD (2011) Exploring news coverage of femicide: Does reporting the news add insult to injury? Feminist Criminology 6(3): 178-202.

Richards TN, Kirkland Gillespie L and Smith MD (2014) An examination of the media portrayal of femicide-suicides: An exploratory frame analysis. Feminist Criminology 9(1): 24-44.

Ryan C, Anastario M and DaCunha A (2006) Changing coverage of domestic violence murders: A longitudinal experiment in participatory communication. Journal of Interpersonal Violence 21(2): 209-228.

Silverstone R (2007) Media and Morality: On the Rise of the Mediapolis. London \& New York: Wiley.

Simons M and Morgan J (2018) Changing media coverage of violence against women: Changing sourcing practices? Journalism Studies 19(8): 1202-1217.

Soothill K, Peelo M, Francis B, et al. (2002) Homicide and the media: Identifying top cases in The Times. The Howard Journal of Criminal Justice 41(5): 401-421.

Sutherland G, McCormack A, Easteal P, et al. (2016) Guidelines for reporting on violence against women in the news media. Australian Journalism Review 38(1): 5-17.

Taylor R (2009) Slain and slandered: A content analysis of the portrayal of femicide in the news. Homicide Studies 13: 21-49. 
Thornborrow J and Montgomery M (2010) Special issue on personalization in the broadcast news interview. Discourse \& Communication 4(2): 99-104.

Vettehen PH, Zhou S and Kleemans M (2012) Competitive pressure and arousing television news: A cross-cultural study. Asian Journal of Communication 22(2): 179-196.

Walsh K, Suiter J and O'Connor O (2015) Hearing Women's Voices? Dublin: National Women's Council of Ireland and Dublin City University.

Women's Aid (2018) Breaking the Pattern of Male Violence. Dublin: Women's Aid.

Women's Aid (2019) Femicide Watch: A Legacy of Loss for Women, Family and Community. Dublin: Women's Aid.

Wozniak JA and McCloskey KA (2010) Fact or fiction? Gender issues related to newspaper reports of intimate partner homicide. Violence Against Women 16(8): 934-952.

\section{Author biographies}

Anne O'Brien is an Associate Professor in the Department of Media Studies at Maynooth University. Her research focuses on gender and creative industries, women's production work and representations of women in broadcasting.

Eileen Culloty is a Postdoctoral Researcher at the Institute for Future Media and Journalism, Dublin City University. Her research examines disinformation, digital literacy and factual representations of conflict and environmental issues. 